\section{Australian Journal of \\ Crop Science}

\title{
Genetic diversity of the germplasm active bank of Capsicum of UNEMAT based on components resistant to the fungus Colletotrichum gloeosporioides
}

\author{
Álan Chrisleyr Maracahipes ${ }^{1}$, Kenia Kelli Coelho Gomes Viscovini ${ }^{2}$, Eduarda da Silva Annunciatto ${ }^{2}$, \\ Leonarda Grillo Neves ${ }^{2}$, Milson evaldo Serafim ${ }^{3}$, Petterson Batist da Luz ${ }^{4}$, Kelly Lana Araújo ${ }^{4}$ \\ ${ }^{1}$ Programa de Pós-Graduação em Genética e Melhoramento de plantas. Universidade do Estado de Mato Grosso \\ (UNEMAT), Brazil \\ ${ }^{2}$ Agronomy department, Universidade Do Estado de Mato Grosso, Brazil \\ ${ }^{3}$ Instituto Federal de Educação, Ciência e Tecnologia de Mato Grosso, Campus Cáceres, Brazil \\ ${ }^{4}$ Agronomy department, Programa de Pós-Graduação em Genética e Melhoramento de plantas, Universidade Do \\ Estado de Mato Grosso, Brazil
}

*Corresponding author: alan.chrisleyr@outlook.com

\begin{abstract}
Peppers and chilies belong to the Solanaceae family and to the genus Capsicum. The production of this vegetable is increasing in Brazil. However, there are several phytosanitary problems that are causing heavy losses to the culture, among them anthracnose. The objective of this study was to evaluate the genetic diversity of the Capsicum Germplasm Active Bank (GAB) of the UNEMAT based on components resistant to the fungus Colletotrichum gloeosporioides. 88 accessions of Capsicum spp., belonging to the Germplasm Active Bank of UNEMAT, were evaluated for reaction to the fungus Colletotrichum gloeosporioides. The experimental design was completely randomized blocks with three replications, being four unripe fruits and four ripe fruits per repetition. Both ripe and unripe fruits were collected from each plot, taken to the laboratory, disinfected and packaged in Styrofoam trays covered with a transparent plastic bag; inside each tray, moistened pieces of filter paper were placed to build the humid chamber. The trays were in an environment with a temperature controlled at $24^{\circ} \mathrm{C} \pm 2$. The evaluation of all the fruits was performed daily based on the measurement of lesion diameter and length of each fruit with an interval of 24 hours between each evaluation for 11 days. The assessment data were subjected to multivariate analysis and to the UPGMA clustering method. There is genetic variability in the GAB of UNEMAT with the formation of different accession groups based on resistance to anthracnose for both clustering methods applied, i.e., UPGMA and Modified Tocher. There was the formation of four groups in the dendrogram, especially regarding the accession 81 (C. аппиит), which had the highest genetic dissimilarity in relation to other accessions, standing isolated in one group. According to the 3D dispersion graph, there was the formation of three groups with genetic dissimilarity among them. According to the modified Tocher method, there was the formation of five groups; the accession 38 ( $C$. chinense) was grouped separately from the other accessions in the group five. The resistance components that had a higher relative contribution to estimate the genetic variability among analyzed accessions were area under the disease progress curve (AUDPC), lesion diameter and length on the seventh day of evaluation (DL7), and incubation period (IP), but it is necessary to use at least seven variables and explain $80 \%$ of the variability of the experiment.
\end{abstract}

Keywords: Anthracnose, Genetic dissimilarity, Pepper, UPGMA, Genetic variability.

Introduction

The Solanaceae family comprises 150 genera and over 3,000 described species. Its possible origin is in Central and South America. In Brazil, it has an occurrence of more than 449 species, including 15 species endemic to the country. The family stands out for its wide commercial, industrial, medical, food and ornamental use. Among the species of the family, potato, tomato, tobacco, pepper and chili are important (Giacomin, 2010). Peppers and chilies belong to the genus Capsicum, with over 35 described species, grown in different parts of the world, especially in tropical countries. Brazil is a major pepper producer. This vegetable is in all regions of the country, especially in the Southeast, Midwest and Northeast. Five species are commonly domesticated:
Capsicum annuum var. annuum; Capsicum baccatum var. pendulum and umbilicatum; Capsicum chinense; Capsicum frutescens; and C.pubescens (Moscone et al., 2007; Carrizo et al., 2013). Pepper is a spice commonly used and appreciated by its pungency, flavor and pharmaceutical properties (Oliveira, 2011). Pepper has been the subject of several studies because it has a rich concentration of chemicals such as capsaicinoids, carotenoids, ascorbic acid, phenolic compounds, vitamin $\mathrm{A}, \mathrm{C}$ and $\mathrm{E}$, and tocopherols. Capsaicinoids are compounds found in several species of peppers. They determine the level of pungency. They have strong antioxidant, antimicrobial, anticancer and analgesic properties. Within the capsaicinoids group, there are more 
than 10 compounds. However, the most studied compound is the alkaloid capsaicin (Keppel, 2007). The market of peppers has gradually been growing. This increase in pepper consumption may be explained by the different uses of the product in natura, in homemade pickles and industrial products such as pastry, jellies and sauces (Wagner, 2003). According to FAO (2014), Brazil is the world's fourth greatest producer of pepper, with an average production of 46,697.33 tons between 2012 and 2013. The production of pepper in Brazil in 2012 was 250,000 tons, making the country one of the greatest producers of pepper in the world (IBGE, 2012). Despite the growing production of this vegetable, there are several phytosanitary problems that have caused significant losses to the culture, including anthracnose, which is considered a major disease of chili and pepper in all producing countries.

Anthracnose in Capsicum is caused by fungi of the genus Colletotrichum such as C. gloeosporioides, C. acutatum, C. capsici, $C$. dematium and $C$. coccodes. In Brazil, anthracnose in Capsicum is caused mainly by the fungus Colletotrichum gloeosporioides, which infects the fruit, and by C. acutatum, which infects different parts of the plant. C. gloeosporioides is also known in the teleomorph form as Glomerella cingulata. It belongs to the subdivision Ascomycota, order Phyllachorales, class Pyrenomycetes and family Phyllachoraceae (Alves et al., 2008). Anthracnose in Capsicum is a complex etiology, characterized as one of the most destructive diseases of peppers and chilies in tropical and subtropical regions, where its dissemination occurs especially in cultures that are made in open field during hot, humid periods. The disease affects mainly the fruit, causing dark-colored necrotic lesions with a circular shape and a variable diameter, from which a mass of spores called conidia emerges (Pereira et al., 2011). The fungus develops mainly during storage. When in environments with favorable temperatures, it reproduces and grows rapidly. Due to its high pathogenic variability, there are difficulties in obtaining cultivars that are more resistant and durable. Therefore, it is extremely important that studies on its genetic diversity be conducted in order to obtain materials that have a genetic resistance to the disease (Viana et al., 2007).

The genetic diversity study is the process by which differences between individuals or groups of individuals or populations are analyzed by a specific method or a combination of methods. The multivariate analysis has been used in some studies on pepper, where the goal is to identify sources of variability and genetic diversity among Capsicum accessions by applying clustering methods aiming to design plant-breeding programs (Sudré et al., 2006; Monteiro et al., 2010). Therefore, the objective of this study is to evaluate the genetic diversity of the Capsicum Germplasm Active Bank of the UNEMAT based on components resistant to the fungus Colletotrichum gloeosporioides.

\section{Results}

All variables were significant by $\mathrm{F}$ test at $1 \%$ significance level. The coefficients of variation ranged from $19.09 \%$ for incubation period of ripe fruits (IPR) to $171.92 \%$ for AUDPC, the latter due to a wide variation between the values for each genotype and the presence of null values for some accessions (Table 2a and 2b). With the application of the clustering methods, a dendrogram, a 3D dispersion analysis graph, a table with a grouping by Modified Tocher and a table with the importance of the characters were obtained.

\section{Dendrogram}

The accessions were distributed to groups by the hierarchical UPGMA clustering method based on the genetic similarity found among genotypes according to the evaluated resistance components. This resulted on a dendrogram with a significant cut between $10 \%$ and $12 \%$, generating six groups genetically distinct, with similarity inside groups and dissimilarity between groups. The first group was formed only by the UNEMAT 38 genotype of the species Capsicum chinense, being divergent in relation to the other treatments. This genotype had a lesion exceeding $70 \%$ of the fruit at the last day of evaluation (day 13). At the seventh day of the lesion evaluation, it had already exceeded $50 \%$ of the fruit.

The second group was subdivided into two groups at $7 \%$. In one subgroup was the UNEMAT 1 genotype identified as Capsicum annuum and in the other subgroup was the UNEMAT genotype 81, Capsicum annuum (Fig.1). The Third group was formed only by the UNEMAT 151 genotype of the species $C$. baccatum var. pendulum. The fourth and fifth group are each formed by 5 accesses. In the fifth group are present accesses 66, 63, 134, 167 and 103, and the sixth group was formed by the access $170,97,39,16$ and 52 . The sixth group was formed by the other 74 accesses.

\section{$3 D$ dispersion analysis}

Based on the genetic similarity of the accessions and using a cluster analysis with a 3D graphical projection, it was possible to observe the formation of three different genotype groups. There were genetic divergences among these groups (Fig. 2). The first group comprises UNEMAT 63 accessions (code 67 in the figure) C. chinense, UNEMAT 103 (code 75) C. annuum, UNEMAT 171 (code 76) C. Baccatum var. pendulum, UNEMAT 56 (code 21) $C$. chinense, UNEMAT 134 (code 81) C. baccatum var. pendulum, UNEMAT 78 (code 71) C. chinense and UNEMAT 151(code 86), identified as $C$. baccatum var. pendulum, which was genetically distinct from other genotypes. The second group comprises 78 accessions that did not have genetic differences among themselves based on the resistance to $C$. gloeosporioides. The third group was formed by UNEMAT 119 accessions (code 58) Capsicum chinense, UNEMAT 116 (code 55) $C$. annuum, and UNEMAT 38 (code 12) $C$. chinense. For groups I and II, the grouping isolated from other accessions was consistent with the grouping performed in the dendrogram, which confirms the genetic variability among these accessions in relation to the others present in the GAB.

\section{Analysis by the modified Tocher optimization method}

By the modified Tocher optimization method, there was a distribution of 88 accessions to five groups (Table 3), highlighting the latter two groups, which showed a greater genetic similarity with other analyzed accessions. The first group consisted of 44 accessions with a genetic similarity among them. The second and the third group were formed by 24 and 14 genotypes, respectively. The third group was formed by five accessions, i.e., UNEMAT 56 Capsicum chinense, UNEMAT 151 C. baccatum var. pendulum, UNEMAT 66 C. baccatum var. baccatum, UNEMAT 63 C. chinense and UNEMAT $81 \mathrm{C}$. annuum. The fifth and last group was formed only by the genotype UNEMAT 38 of the species $C$. chinense. 
Table 1. Identification of the 88 evaluated accessions of Capsicum from the GBA of UNEMAT regarding the genetic resistance to Colletotrichum gloeosporioides.

\begin{tabular}{|c|c|c|c|}
\hline Accession & Identification & Accession & Identification \\
\hline UNEMAT 1 & C. annuиm & UNEMAT 91 & C. frutescens \\
\hline UNEMAT 7 & C. frutescens & UNEMAT 93 & C. chinense \\
\hline UNEMAT 8 & C. chinense & UNEMAT 95 & C. frutescens \\
\hline UNEMAT 9 & C. frutescens & UNEMAT 96 & C. апnuит \\
\hline UNEMAT 10 & C. frutescens & UNEMAT 97 & C. chinense \\
\hline UNEMAT 15 & C. baccatum var. pendulum & UNEMAT 98 & C. chinense \\
\hline UNEMAT 16 & C annuum & UNEMAT 99 & C. апnиит \\
\hline UNEMAT 17 & C. frutescens & UNEMAT 100 & C. chinense \\
\hline UNEMAT 27 & C. frutescens & UNEMAT 101 & C. chinense \\
\hline UNEMAT 29 & C. chinense & UNEMAT 102 & C. chinense \\
\hline UNEMAT 33 & C. frutescens & UNEMAT 103 & C. аппиит \\
\hline UNEMAT 34 & C. frutescens & UNEMAT 104 & C. апnиum \\
\hline UNEMAT 37 & C. chinense & UNEMAT 105 & C. baccatum var. pendulum \\
\hline UNEMAT 38 & C. chinense & UNEMAT 106 & C. chinense \\
\hline UNEMAT 39 & C. chinense & UNEMAT 108 & C. frutescens \\
\hline UNEMAT 43 & C. frutescens & UNEMAT 110 & C. frutescens \\
\hline UNEMAT 44 & C. frutescens & UNEMAT 112 & C. baccatum var. pendulum \\
\hline UNEMAT 46 & C. anпиит & UNEMAT 113 & C. frutescens \\
\hline UNEMAT 47 & C. baccatum var. pendulum & UNEMAT 114 & C. frutescens \\
\hline UNEMAT 48 & C. frutescens & UNEMAT 115 & C. frutescens \\
\hline UNEMAT 49 & C. frutescens & UNEMAT 116 & C. anпиит \\
\hline UNEMAT 51 & C. frutescens & UNEMAT 117 & C. frutescens \\
\hline UNEMAT 52 & C. frutescens & UNEMAT 118 & C. chinense \\
\hline UNEMAT 54 & C. frutescens & UNEMAT 119 & C. chinense \\
\hline UNEMAT 56 & C. chinense & UNEMAT 120 & C. chinense \\
\hline UNEMAT 57 & C. chinense & UNEMAT 125 & C. chinense \\
\hline UNEMAT 59 & C. chinense & UNEMAT 133 & C. baccatum var. pendulum \\
\hline UNEMAT 60 & C. chinense & UNEMAT 134 & C baccatum var. pendulum \\
\hline UNEMAT 62 & C. chinense & UNEMAT 138 & C. baccatum var. pendulum \\
\hline UNEMAT 63 & C. chinense & UNEMAT 141 & C. baccatum var. praetermissum \\
\hline UNEMAT 64 & C. frutescens & UNEMAT 145 & C. chinense \\
\hline UNEMAT 65 & C. baccatum var. pendulum & UNEMAT 148 & C. baccatum var. pendulum \\
\hline UNEMAT 66 & C. baccatum var. pendulum & UNEMAT 151 & C. baccatum var. pendulum \\
\hline UNEMAT 67 & C. frutescens & UNEMAT 152 & C. baccatum var. pendulum \\
\hline UNEMAT 68 & C. frutescens & UNEMAT 163 & C annuum. \\
\hline UNEMAT 69 & C. baccatum var. pendulum & UNEMAT 164 & C. chinense \\
\hline UNEMAT 70 & C. chinense & UNEMAT 165 & C. baccatum var. pendulum \\
\hline UNEMAT 71 & C. chinense & UNEMAT 166 & C. chinense \\
\hline UNEMAT 78 & C. chinense & UNEMAT 167 & C. апnиит \\
\hline UNEMAT 81 & C апnuиm & UNEMAT 168 & C. chinense \\
\hline UNEMAT 83 & C. frutescens & UNEMAT 169 & C. baccatum var. pendulum \\
\hline UNEMAT 84 & C. annum & UNEMAT 170 & C. baccatum var. pendulum \\
\hline UNEMAT 85 & C. chinense & UNEMAT 171 & C. baccatum var. Pendulum \\
\hline UNEMAT 88 & C. baccatum var. pendulum & UNEMAT 172 & C. baccatum var. pendulum \\
\hline
\end{tabular}

\section{Relative contribution of characters}

Upon evaluating the relative contribution of characters for genetic diversity among 88 accessions analyzed using the generalized Mahalanobis Distance, it was observed that seven variables are required to compose $80 \%$ of the diversity found in the experiment, including ruling out the use of canonical variables. The variables with the greatest magnitude in the experiment, in a descending order of contribution, are AUDPC for unripe fruits with a $15.54 \%$ contribution, LD7 with $10.91 \%$, LL7 with $8.60 \%$, LR of ripe fruits with $7.93 \%$, IP of ripe fruits with $7.36 \%$, IP of unripe fruits with $7.14 \%$, and LD7 of ripe fruits with $7.02 \%$ (Fig. 3).

Thus, for this experiment, AUDPC had the greatest contribution to genetic diversity among the accessions analyzed, even with $58.05 \%$ and $171.92 \%$ coefficients of variation for unripe and ripe fruits, respectively.

\section{Discussion}

In this study, it was observed that within each group formed by clustering methods, there are different species, proving they are genetically close as for the response reaction to the fungus $C$. gloeosporioides. Sudré et al. (2005), upon applying multivariate techniques to evaluate the genetic divergence among 56 accessions of the germplasm collection of Capsicum spp. of the UENF, based on key morphological and agronomic descriptors, obtained a dendrogram with the formation of seven genetically distinct groups among themselves, with different species within each group. Monteiro et al. (2010) evaluated the genetic divergence among 23 accessions of pepper from the genus Capsicum from 7 quantitative descriptors and 19 multicategoric qualitative descriptors with the help of multivariate techniques. It resulted in the formation of three groups based on quantitative descriptors and four groups based on 


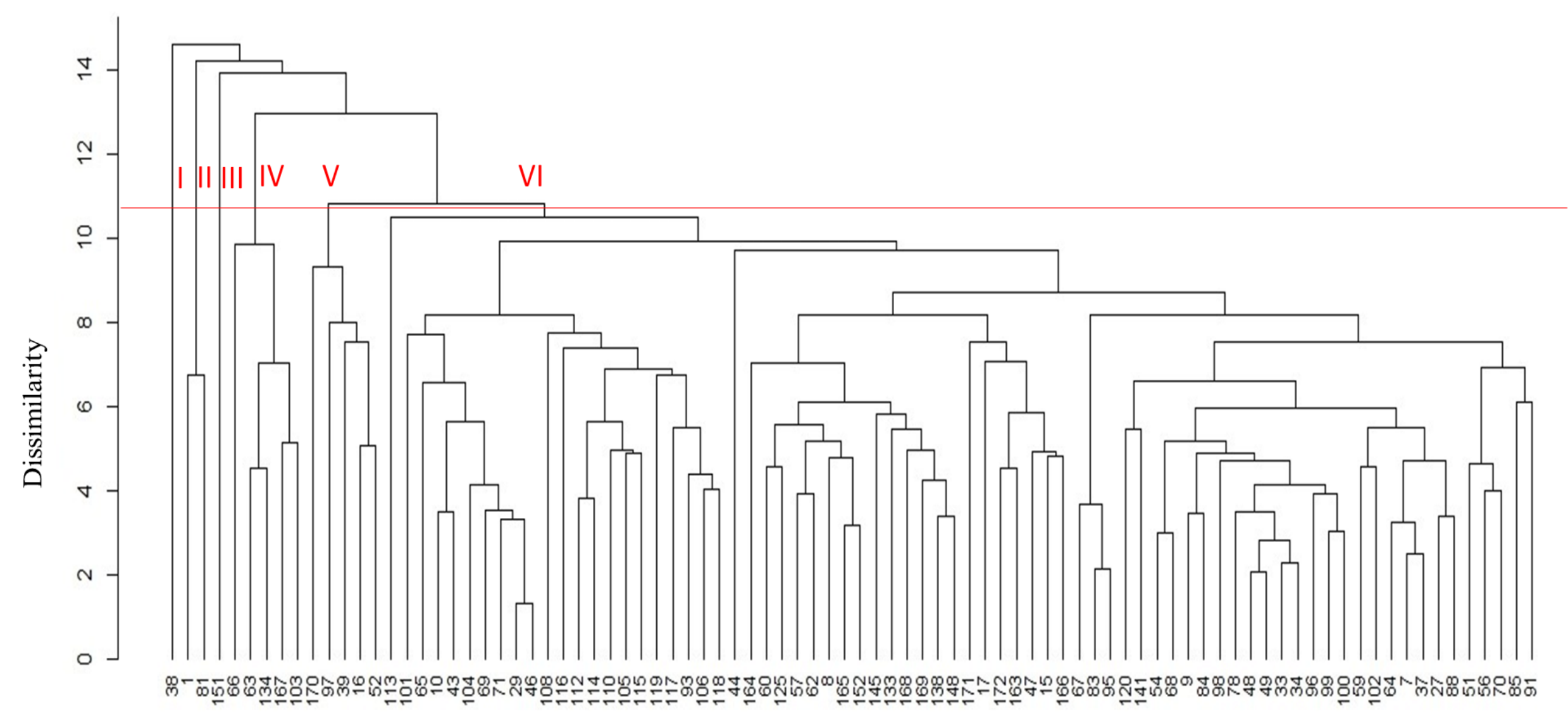

Fig 1. Dendrogram of the genetic similarity among the 88 accessions from the GAB of UNEMAT with a cutting between $10 \%$ and $12 \%$ significance level, with the formation of six genetically distinct. 
Table 2(a). Analysis of variance of the evaluation of 88 Capsicum spp. accessions from the Germplasm Active Bank of UNEMAT resistant to Colletotrichum gloeosporioides.

\begin{tabular}{|c|c|c|c|c|c|c|c|c|c|c|}
\hline \multirow{2}{*}{ FV } & \multirow{2}{*}{ DF } & \multicolumn{9}{|c|}{ Mean squares } \\
\hline & & IP & LP & NDLR50DF & NDLA50CF & LD7 & LL7 & DR & LR & AUDPC \\
\hline Blocks & 2 & 0.3984 & 0.5798 & 0.2979 & 12.8864 & 3.9851 & 7.8375 & 70.0043 & 76.7448 & 92986.2584 \\
\hline Treatments & 87 & $3.4468 * *$ & $4.6983 * *$ & $27.7126 * *$ & $104.4219 * *$ & $37.8389 * *$ & $105.8236 * *$ & $972.5013 * *$ & $1,375.0175^{* *}$ & $1,311,169.4283 * *$ \\
\hline Residue & 174 & 1.1686 & 2.8111 & 5.0219 & 13.6092 & 4.3636 & 8.9758 & 520.7208 & 355.5731 & $144,560.2758$ \\
\hline Mean & & 2.99 & 5.43 & 6.06 & 8.56 & 6.87 & 9.15 & 89.86 & 89.61 & 655.02 \\
\hline CV $(\%)$ & & 36.20 & 30.90 & 36.95 & 43.11 & 30.39 & 32.74 & 24.26 & 22.33 & 58.05 \\
\hline
\end{tabular}

** significant at 1\% probability by F test. Incubation period (IP); Latent period (LP); Number of days until the lesion reached 50\% of the fruit length (ND50L); Number of days until the lesion reached 50\% of the fruit diameter (ND50D); Lesion ** significant at $1 \%$ probability by $\mathrm{F}$ test. Incubation period (IP); Latent period (LP); Number of days until the lesion reached $50 \%$ of the fruit length (ND50L); Number of days until the lesio
Diameter at the seventh day of evaluation (LD7); Lesion length at the seventh day of evaluation (LL7); Diameter ratio (DR); Length ratio (LR); Area under the disease progress curve (AUDPC).

Table 2(b). Analysis of variance of the evaluation of 88 Capsicum spp. accessions from the Germplasm Active Bank of UNEMAT resistant to Colletotrichum gloeosporioides.

\begin{tabular}{|c|c|c|c|c|c|c|c|c|c|c|}
\hline \multirow{2}{*}{ FV } & \multirow{2}{*}{$\mathrm{DF}$} & \multicolumn{9}{|c|}{ Mean squares } \\
\hline & & IP & LP & ND50D & ND50L & LD7 & LL7 & DLR & LLR & AUDPC \\
\hline Blocks & 2 & 1.4669 & 2.6174 & 1.7971 & 6.7196 & 11.1340 & 27.1783 & 568.8072 & 145.0616 & $3,503,512.9545$ \\
\hline Treatments & 87 & $3.3899 * *$ & $5.5797 * *$ & $6.5692 * *$ & $10.7117 * *$ & $34.1679 * *$ & $49.4744 * *$ & $726.8477 * *$ & $1,726.6388^{* *}$ & $4,465,528.5830^{* *}$ \\
\hline Residue & 174 & 0.3915 & 0.9095 & 1.4068 & 3.4756 & 5.8497 & 13.7371 & 219.2041 & 326.9275 & $2,353,589.6740$ \\
\hline Mean & & 2.74 & 5.47 & 5.03 & 5.96 & 8.88 & 10.89 & 93.12 & 81.03 & 892.33 \\
\hline CV (\%) & & 22.82 & 19.09 & 23.99 & 31.28 & 27.23 & 34.05 & 15.90 & 24.42 & 171.92 \\
\hline
\end{tabular}

** significant at $1 \%$ probability by $\mathrm{F}$ test. Incubation period (IP); Latent period (LP); Number of days until the lesion reached 50\% of the fruit length (ND50L); Number of days until the lesio
Diameter at the seventh day of evaluation (LD7); Lesion length at the seventh day of evaluation (LL7); Diameter ratio (DR); Length ratio (LR); Area under the disease progress curve (AUDPC).

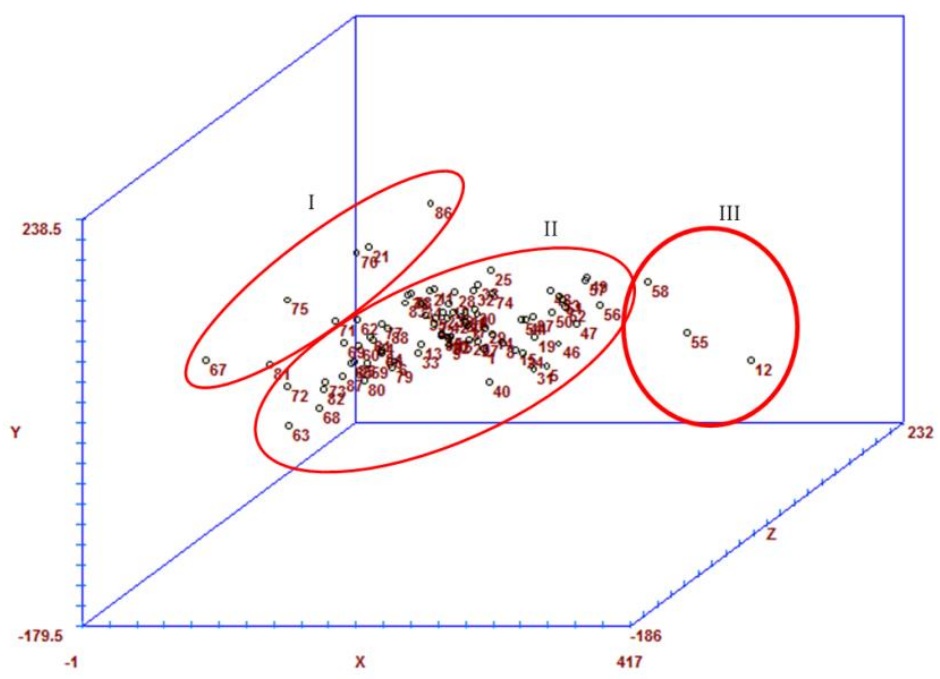

Fig 2. 3D dispersion graph using the UPGMA clustering method of the 88 accessions of Capsicum spp. from the GAB of UNEMAT, where there was the formation of three genetically distinct groups, with genetic similarity between accesses of the same group. 
Table 3. Grouping by Modified Tocher optimization of 88 accessions of Capsicum spp. from the GAB of UNEMAT based on 18 components resistant to Colletotrichum gloeosporioides.

\begin{tabular}{|c|c|}
\hline Groups formed & Genotypes \\
\hline 1 & $\begin{array}{llllllllllllllllllllll}29 & 46 & 71 & 69 & 104 & 43 & 10 & 115 & 93 & 106 & 114 & 105 & 110 & 112 & 68 & 98 & 34 & 99 & 64 & 59 & 48 \\
49 & 33 & 9 & 100 & 54 & 78 & 84 & 96 & 27 & 88 & 65 & 96 & 37 & 83 & 7 & 67 & 102 & 141 & 57 & 145 & 120 & 62 \\
163 & & & & & & & & & & & & & & & & \end{array}$ \\
\hline 2 & $\begin{array}{lllllllllllllllllll}64 & 152 & 148 & 138 & 8 & 169 & 133 & 168 & 164 & 125 & 60 & 166 & 15 & 47 & 167 & 172 & 134 & 17 & 39 \\
171 & 44 & 91 & 85 & 103\end{array}$ \\
\hline 3 & $\begin{array}{llllllllllllll}16 & 52 & 97 & 170 & 70 & 51 & 1 & 117 & 118 & 119 & 116 & 108 & 113 & 101\end{array}$ \\
\hline 4 & $\begin{array}{lllll}56 & 151 & 66 & 63 & 81\end{array}$ \\
\hline 5 & \\
\hline
\end{tabular}

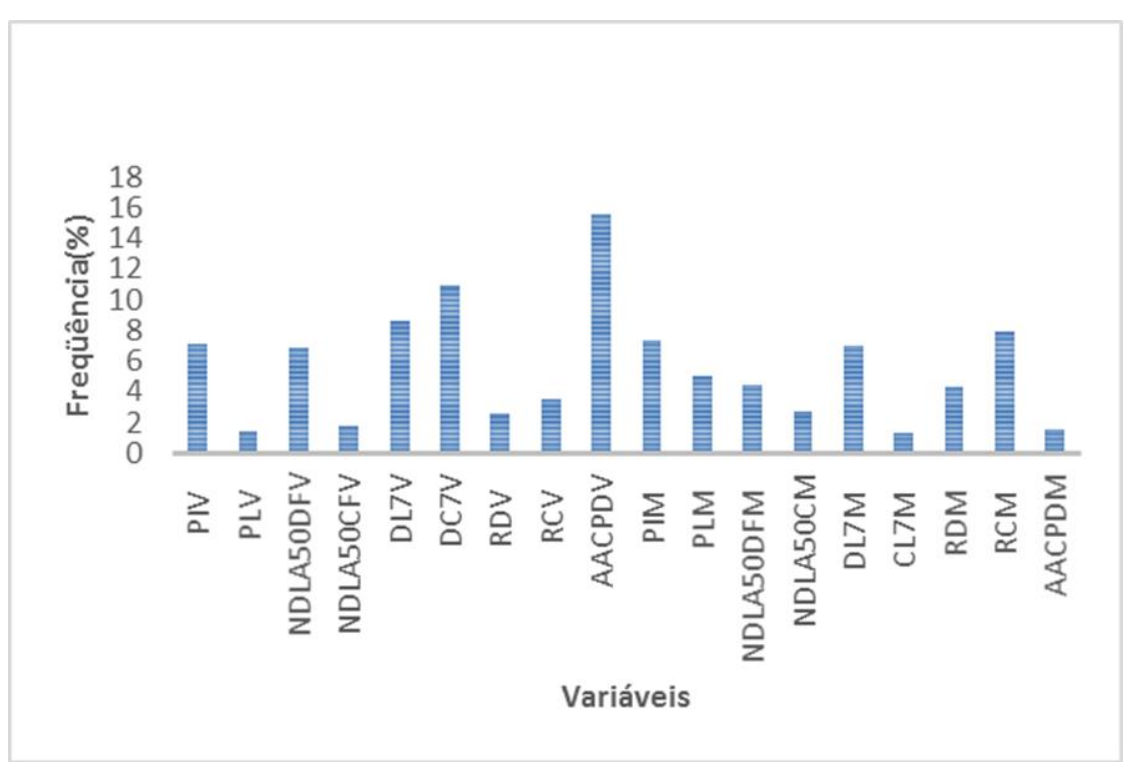

Fig 3. Relative contribution of the 18 characters evaluated, nine for unripe fruits (U) and nine for ripe fruits (R), as follows: Incubation period (IP); Latent period (LP); Number of days until the lesion reached 50\% of the fruit diameter (NDLR50D); Number of days until the lesion reached 50\% of the fruit length (NDLR50L); Lesion Diameter at the seventh day of evaluation (LD7); Lesion length at the seventh day of evaluation (LL7); Diameter ratio (DR); Length ratio (LR); Area under the disease progress curve (AUDPC) in a multivariate analysis.

qualitative descriptors using the UPGMA method. In this study, there was also the formation of four groups using UPGMA based on the components resistant to $C$. gloeosporioides, data that can be seen in the dendrogram. In a study by Neitzke et al. (2010), in which the objective was to characterize and study the genetic distance of accessions, with an ornamental potential, of the Germplasm Active Bank of Capsicum of the Embrapa Temperate Climate, also using the UPGMA clustering method, the result was the formation of three groups genetically distant by quantitative characteristics and six groups by the evaluation of qualitative characteristics. It was found in the aforementioned work that it was not possible to genetically separate species in each group formed, a fact that also occurred in this study, where the three formed groups (II, III and IV) had varied species. Multivariate techniques were used by Ferrão et al. (2011) to evaluate genetic divergence among 34 subsamples of the germplasm collection of Capsicum baccatum. Based on two canonical variables, subsamples were separated into five distinct groups with a genetic variability among them. The grouping method used allowed visualizing the genetic variability among 34 pepper subsamples. This can also be observed in the methods employed in this study, where almost all evaluated accessions had a reaction similar to fungus infection for almost all variables.
Monteiro et al. (2010) applied the Tocher optimization grouping method to 23 pepper accesses from 7 quantitative descriptors and 19 qualitative multicategoric descriptors. They detected the formation of eight groups, both for quantitative descriptors and qualitative multicategoric descriptors. Using the modified Tocher grouping test, there was the formation of five genetically distinct groups, confirming that there are differences among accessions in relation to resistance or susceptibility response. Vasconcelos et al. (2012), upon verifying the efficiency of multicategoric descriptors of flowers to estimate the genetic dissimilarity among Capsicum chinense accessions from the Capsicum Germplasm Active Bank, with groupings using UPGMA and Tocher methods for quantitative data, and one grouping using the Tocher method for qualitative and quantitative data, obtained a dendrogram with the formation of four distinct groups and the formation of three groups using qualitative data and 10 groups using quantitative data through the Tocher method. That work also concluded that multicategoric descriptors of flowers are efficient to estimate the genetic dissimilarity among accessions, a fact also observed in this study, because the use of resistance components to infer the genetic diversity in a GAB was effective.

The groups formed by the optimization method were similar to the grouping represented by the hierarchical clustering methods UPGMA and 3D dispersion graph. The accessions UNEMAT 151 Capsicum baccatum var. 
pendulum, UNEMAT 63 C. chinense, UNEMAT 56 C. chinense, UNEMAT 66 C. baccatum, UNEMAT $38 C$. chinense and the accession UNEMAT $81 C$. апnиum were always emphasized and isolated from the other groups, thus being in concordance. This was also observed by Arriel et al. (2006). Upon comparing different multivariate techniques in the characterization of 35 sesame genotypes using 769 RAPD markers, they concluded that among hierarchical clustering methods, UPGMA has the best adjustment to original and estimated distances, and UPGMA and Tocher optimization methods are complementary in the formation of clusters.

Faria et al. (2012) compared three methods for determining the number of groups in studies with the application of hierarchical clustering methods based on data obtained from the characterization of 49 Capsicum accessions. The Tocher method showed the formation of four groups: three groups had only one accession. In this work, only one group (group 5) had only a single genotype, revealing the dissimilarity of this genotype (UNEMAT 38) in relation to the other genotypes.

In the evaluation, other prominent variables that greatly contributed to the genetic diversity of accession were length and lesion diameter at the seventh day of evaluation, with great differences in measurements among treatments. This is because in some of the susceptible accessions, the lesion had already reached $100 \%$ of the fruit at the seventh day, which did not happen with resistant accessions. This variable gained a fundamental importance for disease resistance analysis.

Pedrosa et al. (2004) evaluated the components of resistance of eight cultivars and two onion accessions (Allium cepa) to four isolates of $C$. gloeosporioides inoculated by an inoculum suspension atomization or deposition of mycelium discs in leaves. In this experiment, seven resistance components similar to the components present in this work were evaluated: AUDPC, incubation period, latent period and severity of the disease. The authors concluded that the severity of the disease at nine days of evaluation (SEV9) was potentially useful in evaluating the resistance of onion germplasm to $C$. gloeosporioides, while in this work, AUDPC and CD7 were more relevant.

\section{Materials and Methods}

\section{Experiment conditions}

The study was conducted in the municipality of Caceres, Mato Grosso, located between the latitudes $15^{\circ} 27^{\prime}$ and $17^{\circ} 37^{\prime}$ south and longitudes $57^{\circ} 00^{\prime}$ and $58^{\circ} 48^{\prime}$ west at an altitude of $118 \mathrm{~m}$. According to the Köppen classification, the climate is tropical hot and humid with a dry winter (Awa). The average annual temperature is $26^{\circ} \mathrm{C}$. There is a four-month rainy season (December to March) and an eight-month dry period (April to November) (Neves et al., 2011). Accessions were collected from farms in the southwestern part of Mato Grosso state.

The field experiment was conducted using a randomized blocks design (RBD) with three replications and two plants per replication. First, the production of Capsicum spp. seedlings was performed in a greenhouse protected from accessions stored in the Germplasm Active Bank (GAB) in a refrigerator using commercial substrate in Styrofoam trays with 128 cells. When the seedlings reached $10 \mathrm{~cm}$ in height, they were transplanted into disposable cups. After 45 days, they were planted in beds with a $0.8 \mathrm{~m}$ space between plants and $1.2 \mathrm{~m}$ between rows. Cultural treatments were performed as recommended for the culture according to Filgueira
(2013). The irrigation system was done by dripping, and autocompensant drips were used.

\section{Inoculation and evaluation of the fungus Colletotrichum gloeosporioides in Capsicum fruits}

Ripe and unripe fruits were collected from each plot 40 days after anthesis, brought to the Plant Breeding Laboratory (LMGV) of the State University of Mato Grosso, disinfected with $70 \%$ alcohol and sodium hypochlorite $(0.5 \%)$, and washed in sterile distilled water for one minute at each step. Later, they were packaged in Styrofoam trays covered with a transparent plastic bag; inside each tray, moistened pieces of filter paper were placed to build the humid chamber. Eightyeight Capsicum spp. accessions (Table 1) were evaluated for resistance to the fungus $C$. gloeosporioides in a completely randomized experimental blocks design (RCB) with three replications, with four unripe fruits and four ripe fruits per replication.

For the inoculation, the fungus $C$. gloeosporioides was grown in a PDA culture medium (potato dextrose agar) and kept in BOD with a photoperiod of 12 hours and a temperature of $24^{\circ} \mathrm{C}$ for seven days. After this period, the amount of spore suspension was adjusted to $10^{6}$ conidia $/ \mathrm{mL}$, with the aid of a mirrored Neubauer chamber. A cut was done in each fruit at the middle region with a sterile needle. In three ripe fruits and three unripe fruits, the inoculation of the fungus was made by depositing a droplet containing $20 \mu \mathrm{L}$ of spore suspension. One unripe fruit and one ripe fruit from each plot constituted the witness group, to which $20 \mu \mathrm{L}$ of sterile distilled water was deposited.

The trays were in an environment with a controlled temperature at $24^{\circ} \mathrm{C} \pm 2$. The evaluation of all fruits was daily made based on the measurement of the lesion diameter and length of each fruit in an interval of 24 hours for each evaluation for 13 days.

\section{Multivariate analysis and resistance components}

The evaluation data were subjected to a multivariate analysis using the generalized Mahalanobis distance and the UPGMA clustering method. The GENES software was used based on nine components resistant to anthracnose in Capsicum spp. fruits. They were applied to both unripe and ripe fruits, totaling 18 variables for each accession. The resistance components evaluated were

a) Incubation Period (IP): period between inoculations of the pathogen until the onset of symptoms in the fruit. The incubation period was evaluated for the three fruits per replication and the mode was calculated by generating a value for each repetition of each genotype.

b) Latent period (LP): period from the inoculation of the pathogen until the appearance of the first reproduction structures, i.e., the appearance of conidia. The latent period was evaluated for three fruits per replication and the mode was calculated by generating a value for each replication of each genotype.

c) Number of days until the lesion reached $50 \%$ of the fruit length (ND50): number corresponding to the number of days that the lesion took to reach $50 \%$ of the fruit within the evaluation period of 11 days. After this period, the lesions that did not reach $50 \%$ of the fruit had a null value. The mode for each replication was also calculated. 
d) Number of days until the lesion reached $50 \%$ of the fruit diameter (NDLR50FD): number corresponding to the number of days that the lesion took to reach $50 \%$ of the fruit diameter within the assessment period of 11 days. After this period, the lesions that did not reach $50 \%$ of the fruit had a null value. The mode for each replication was also calculated.

e) Lesion diameter at the seventh day of evaluation (LD7): diameter of the lesion of each fruit of each replication at the seventh day of evaluation. Then, an average was calculated for each replication.

f) Length of lesion at the seventh day of evaluation (LL7): length of the lesion of each fruit of each replication at the seventh day of evaluation. Then, an average was calculated for each replication.

g) Diameter ratio (DR): ratio between lesion diameter at the last day of evaluation and diameter of the fruit. It was calculated according to the formula $\mathrm{DR}=$ (Lesion diameter $\mathrm{x}$ 100) / fruit diameter. This formula was applied to all fruits; then, an average for each treatment was calculated.

h) Length ratio (LR): ratio between lesion length at the last day of evaluation and the length of the fruit. It was calculated according to the formula DR = (lesion length $\mathrm{x} 100$ ) / fruit length. This formula was applied to all fruits; then, an average for each treatment was calculated.

i) Area under the disease progress curve (AUDPC): first, the area for each evaluation day for each product analyzed was calculated according to the formula ( $\pi$ *diameter*length) $/ 4$. Then, the area under the disease progress curve was calculated using the formula of Shaner and Finney (1977), calculating an average for each replication.

\section{Conclusion}

There is a genetic variability in the Germplasm Active Bank of UNEMAT, with the formation of groups of genetically different accessions based on the resistance to anthracnose for both clustering methods applied. The accession 81 was emphasized: it had the highest genetic dissimilarity in relation to other accessions using UPGMA methods, and the accession 38 was grouped in isolation from other accessions by the modified Tocher method. The resistance components that had a higher relative contribution to estimate the genetic variability among analyzed accessions were area under the disease progress curve (AUDPC), lesion diameter and length on the seventh day of evaluation (DL7) and incubation period (IP), but it is necessary to use at least seven variables and explain $80 \%$ of the variability of the experiment.

\section{Acknowledgements}

We thank the funding agencies CNPq, CAPES and FAPEMAT for the financing of this work and for the scholarship.

\section{References}

Alves KF, Laranjeira D, Câmara MPS, Câmara CAG, Michereff S. (2015) Efficacy of plant extracts for control of Colletotrichum acutatum in bell pepper fruits. Hort Bras. 33: 332-338.
Arriel NHC, DI Mauro AO, DI Mauro SMZ, Bakke OA Unêda-Trevisoli SH, Costa MM, Capeloto A, Corrado AR (2006) Técnicas multivariadas na determinação da diversidade genética em gergelim usando marcadores RAPD. Pesq Agrop Bras. 41: 801-809.

Carrizo GC, Sterpetti M, Volpi P, Ummarino M, Saccardo F (2013) Wild Capsicums: identification and in situ analysis of Brazilian species. Paper presented at the XVth EUCARPIA Meeting on genetics and breeding of Capsicum and Eggplant, Italy, 02-04 September 2013.

FAO (Food and Agriculture Organization of the United Nations) (2014) FAOSTAT. Available at: http://faostat3.fao.org/browse/Q/QC/E. (Accesed 20 November 2014).

Faria PN, Cecon PR, Silva AR, Finger FL, Silva FF, Cruz CD, Sávio FL (2012) Métodos de agrupamento em estudo de divergência genética de pimentas. Hort Bras. 30: 428432.

Ferrão LFV, Cecon PR, Finger FL, Silva FF, Puiatti M (2011) Divergência genética entre genótipos de pimenta com base em caracteres morfo-agrônomicos. Hort Bras. 29: 354-358.

Filgueira FAR (2013) PARTE II - Olericultura especial. In: FILGUEIRA FAR (ed) Novo manual de olericultura: agrotecnologia moderna na produção e comercialização de hortaliças, 3 ed. UFV, Viçosa.

Giacomin LL (2010) Estudos taxonômicos e filogenéticos em Solanum sect. Gonatotrichumbitter (Solanoideae, Solanaceae) no Brasil. Universidade Federal de Minas Gerais, Belo Horizonte, Brasil.

IBGE/SIDRA (Instituto Brasileiro de Geografia e Estatística) (2012) Levantamento sistemático da produção agrícola. Available

http://www.ibge.gov.br/home/estatistica/indicadores/agrope cuaria/lspa/. (Acesso 15 November 2014).

Keppel VD (2007) Avaliação das propriedades antioxidantes e antimicrobiana de extratos de Capsicum baccatum L. var. pendulum. Universidade do Rio Grande do Sul, Porto Alegre, Brasil.

Monteiro ER, Bastos EM, Lopes ACA, Gomes RLF, Nunes JAR (2010) Diversidade genética entre acessos de espécies cultivadas de pimentas. Ciênc Rural. 40: 288-283.

Moscone EA, Scaldaferro MA, Grabiele M, Cecchini NM, Garcia YS, Jarret R, Daviña JR, Dacasse DA, Barboza GE, Ehrendorfer F (2007) The Evolution of Chili Peppers (Capsicum - Solanaceae): a Cytogenetic Perspective. Acta Hort. $745: 137-169$.

Neitzke RS, Barbieri RL, Rodrigues WF, Corrêa IV, Carvalho FIF (2010) Dissimilaridade genética entre acessos de pimenta com potencial ornamental. Hort Bras. 28: 4753.

Neves SMA, Nunes MCM, Neves NJ (2011) Caracterização das condições climáticas de Cáceres/ MT-Brasil, no período de 1971 a 2009: subsídio às atividades agropecuárias e turísticas municipais. Boletim Goiano de Geografia. 31: 55-68.

Oliveira AMC (2011) Caracterização química, avaliação da atividade antioxidante in vitro e atividade antifúngica de pimentas do gênero Capsicum ssp. Universidade Federal do Piauí, Teresina, Brasil.

Pedrosa RA, Maffia LA, Mizubuti ESG, Brommonschenkel SH (2004) Componentes de resistência em cebola a Colletotrichum gloeosporioides. Fitopat Bras. 29:606-613. 
Pereira MJZ, Massola Junior NS, Sussel AAB, Sala FC, Costa CP, Boiteux LS (2011) Reação de acessos de Capsicum e de progênies de cruzamentos interespecíficos a isolados de Colletotrichum acutatum. Hort Bras. 29: 569576.

Shaner G, Finney RE (1977) The effect of nitrogen fertilization on the expression of slow-mildewing resistence in knox wheat. Phytopathology. 67:1051-1056.

Sudré CP, Rodrigues R, Riva EM, Karasawa M, Amaral Júnior AT (2005) Divergência genética entre acessos de pimenta e pimentão utilizando técnicas multivariadas. Hort Bras. 23: 22-27.

Sudré CP, Cruz CD, Rodrigues R, Riva EM, Amaral Júnior AT, Silva DJH, Pereira TNS (2006) Variáveis multicategóricas na determinação da divergência genética entre acessos de pimenta e pimentão. Hort Bras. 24: 88-93.
Vasconcelos CS, Barbieri RL, Neitzke RS, Priori D, Fischer SZ, Mistura CC (2012) Determinação da dissimilaridade genética entre acessos de Capsicum chinense com base em características de flores. Rev Ceres. 59: 493-498.

Viana FMP, Freire FCO, Parente GB (2007) Controle das principais doenças do pimentão cultivado nas regiões serranas do estado de Ceará (Comunicado Técnico). EMBRAPA. 132: 1-4.

Wagner CM (2003) Variedade e base genética da pungência e de caracteres do fruto: implicações no melhoramento de uma população de Capsicum annuum L. Escola Superior de Agricultura "Luiz de Queiroz”, Piracicaba, Brasil. 